\title{
Risk Factors for Self-Reported Colon Polyps
}

Henry S. Kahn, MD, Lilith M. Tatham, DVM, MPH, Michael J. Thun, MD, MS,

Clark W. Heath, Jr., MD

OBJECTIVE: Investigate risk factors for colon polyp using multivariate analyses.

DESIGN: In a group responding to a 1992 mail survey, we assessed the association between physician-diagnosed colon polyp and possible risk factors reported primarily 10 years earlier.

SETTING: Survey respondents within the Cancer Prevention Study II.

PARTICIPANTS: Respondents, 72,868 men and 81,356 women, who reported no polyp diagnosis when questioned in 1982 at ages 40 to 64 years.

MEASUREMENTS AND MAIN RESULTS: The characteristics of 7,504 men (10.3\%) and 5,111 women (6.3\%) reporting a first colon polyp were compared with those of participants who did not report a polyp. After adjustments for age, family history of colorectal cancer, and other potential risk factors, polyp occurrence was associated with 1982 histories of smoking, former smoking, alcohol use of at least two drinks per day (odds ratios [ORs] from 1.5 to 1.1 ; all $p<.005$ ), and a body mass index $\geq 28 \mathrm{~kg} / \mathrm{m}^{2}$ (men's OR 1.06; $95 \%$ confidence interval [CI] 1.00, 1.13; women's OR 1.08; 95\% CI 0.99, 1.17). Polyps were also associated with a diagnosis of gallbladder disease or gallstone at any time and with gallbladder surgery up to 1982 (OR from 2.7 to 1.3; all $p<.001$ ). Polyp occurrence was inversely associated with 1982 histories of high exercise level (men's OR 0.83; 95\% CI 0.76, 0.91; women's OR 0.90; 95\% CI 0.78, 1.03), frequent aspirin use in women (OR $0.85 ; 95 \% \mathrm{CI} 0.77,0.95$ ), and high parity in women (OR 0.84 ; 95\% CI 0.75, 0.94). Among participants lacking a clinically normal gallbladder, the polyp risks associated with smoking and high body mass index were reduced $(p<.04$ for interactions).

CONCLUSIONS: Despite the limitations and potential biases in these self-reported data, the risk factors described here may be useful for identifying persons at modestly increased risk of having a colon polyp. The effect-modifying role of gallbladder status deserves further investigation.

KEY WORDS: colon; gallbladder diseases; polyp; risk factors; smoking.

J GEN INTERN MED 1998;13:303-310.
Creening and removal of colon polyps are major reaSons that underlie the estimated 3.5 million colonoscopies and flexible sigmoidoscopies occurring annually in the United States. ${ }^{1}$ Colon polyps are important for their relation to colorectal cancer. Adenomatous polyps are considered to be precursor lesions, ${ }^{2-4}$ while hyperplastic polyps may be markers for populations at high risk of colorectal cancer. ${ }^{5}$ Early and repeated screening for colon polyps is generally recommended among adults with a personal or first-degree family history of colorectal neoplasia or inflammatory bowel disease, ${ }^{6-10}$ but proposals to screen persons at otherwise "average risk" have been criticized for their financial cost, low patient acceptability, and possible adverse effects. ${ }^{11}$ It may be useful, therefore, to investigate other polyp risk factors that could improve the recognition of those average-risk adults who are most likely to benefit from polyp screening.

Dozens of case-control studies have examined colon polyp risk factors such as diet, cigarette smoking, alcohol use, physical activity, obesity, and prior cholecystectomy. (For general reviews, see Neugut et al. ${ }^{12}$ and Peipins and Sandler. ${ }^{13}$ ) Two population-based, prospective cohorts, the Health Professionals Follow-up Study and the Nurses' Health Study, have reported on characteristics associated with adenomatous colon polyps ${ }^{14-22}$ and hyperplastic colon polyps ${ }^{5}$ during an observation period of up to 10 years. These prospective cohorts yielded detailed epidemiologic insights in part because their participants were highly educated health professionals who underwent endoscopic screening. We have examined the risk factors associated with colon polyp diagnosis in a large study population drawn from a wider range of occupations and social class.

\section{METHODS}

\section{Study Population}

Participants were drawn from the American Cancer Society's Cancer Prevention Study II (CPS-II), ${ }^{23}$ a large, mortality follow-up survey based on a 4-page confidential questionnaire in 1982 ("baseline") about personal and medical history, diet, cigarette smoking, and alcohol consumption. Volunteers throughout the United States and Puerto Rico enrolled their neighbors, acquaintances, and relatives by family groups in which at least one household member was age 45 years or older. The CPS-II population of nearly 1.2 million people contained proportionately more educated persons and fewer nonwhites and poor persons than in the general U.S. population. Ten years later the American Cancer Society mailed a more extensive survey questionnaire to a selected subset of the CPS-II
Received from the Department of Epidemiology and Surveillance Research, American Cancer Society, Atlanta, Ga. Dr. Kahn is also affiliated with the Department of Family and Preventive Medicine, Emory University School of Medicine, Atlanta, Ga.

Address correspondence to Dr. Kahn and reprint requests to Dr. Thun: Epidemiology and Surveillance Research, American Cancer Society, Atlanta, GA 30329-4251. 
cohort with the goal of collecting more detailed dietary and other risk-factor information. The 1992 survey was mailed to CPS-II husband-wife pairs who lived in 21 selected states and were then between the ages of 50 and 74 years.

Our analytic groups were drawn from the 82,878 men and 95,061 women who responded to the 1992 survey questionnaire and were ages 40 through 64 at the baseline survey. This analysis excluded persons who did not explicitly answer the 1992 survey question, "Has a physician ever diagnosed you with colon polyp(s)?" (3.0\% of the men, $3.4 \%$ of the women), those reporting at baseline a physician's diagnosis of colon or rectal polyps $(6.3 \%$ of the men, $4.0 \%$ of the women), those who did not provide adequate baseline information on smoking history ( $2.7 \%$ of the men, $4.8 \%$ of the women), and those who reported a major cancer (of the colon, rectum, bronchus, lung, breast, or prostate) at baseline $(0.6 \%$ of the men, $3.0 \%$ of the women). Among CPS-II survivors potentially eligible for inclusion in this study, the survey participation rate in 1992 was $41 \%$ for the men and $35 \%$ for the women.

The 72,868 men remaining in the analytic group described their present or former occupation most frequently as managers/executives (21\%), teachers $(8 \%)$, sales/retail clerks (8\%), engineers/architects (7\%), farmers/fishermen (4\%), and health professionals (mostly doctors) (3\%). The 81,356 women remaining in the analytic group described themselves most frequently as housewives (41\%), office workers/bookkeepers (15\%), teachers (10\%), and health professionals (mostly nurses) (7\%). College graduation had been attained by $46 \%$ of the men and $31 \%$ of the women. Eight percent of the men and $5 \%$ of the women had not completed high school. The racial/ ethnic composition of both the male and female groups was $97.3 \%$ white and non-Hispanic.

\section{Questionnaires}

Self-reports (in 1982) of height, weight, educational status, race/ethnicity, smoking history, aspirin use, vitamin supplementation, exercise "at work or play" (categorized as "none/slight," "moderate," or "heavy"), history of gallstones, history of gallbladder surgery, family history of colorectal cancer, and (for women) parity, menopausal status, and estrogen use were provided by CPS-II. The CPS-II baseline diet history asked for the current days per week the participant consumed each of 28 food items or groups, including 6 of red meats, 6 of vegetables, 4 of highfiber foods, and 1 each of citrus fruits/juices, chicken, fish, and eggs. The questionnaire also asked if there had been a major diet change in the past 10 years. The beverage history asked for the current number of cups, glasses, or drinks per day the participant consumed of caffeinated coffee, decaffeinated coffee, beer, wine, and hard liquor.

The 1992 survey asked if a physician had ever diagnosed a colon polyp, gallstones or gallbladder disease, or cancer at major sites. No information was available in 1992 on the date, site, or histology of the reported colon polyps, gallbladder surgery, the respondents' medical visits, or experience with polyp screening.

\section{Data Analysis}

Participants' self-reports in 1982 were used to categorize their baseline exposures to smoking, alcohol (sum of beer, wine, and liquor), aspirin, coffee (with or without caffeine), ${ }^{24,25}$ vitamin supplementation, exercise, and gallbladder surgery. Family history of colorectal cancer was categorized at baseline as none, one first-degree relative, or two or more first-degree relatives. For estimating intake of red meats (sum of 6 items), vegetables and fruit (sum of 7 items), and high-fiber foods (sum of 4 items), gender-specific deciles were calculated for each food group's intake in days per week; the referent group (first decile) was compared with deciles 2 through 5, deciles 6 through 9, and decile 10. Egg intake ${ }^{26,27}$ was categorized as less than 1 day/ week, 1-4 days/week, or 5-7 days/week. Chicken plus fish intake $^{14}$ was categorized as 1 or less days/week, 2-4 days/ week, or 5-7 days/week. A major dietary change in the past 10 years was coded as no or yes.

Baseline self-reports also established a history of gallbladder surgery up to 1982, baseline body mass index $\left(\mathrm{kg} / \mathrm{m}^{2}\right)$, parity, menopausal status, and use of estrogen replacement therapy. Participants were classified as having a "gallbladder disease or stone" if they did not report gallbladder surgery at baseline but described either gallstones (on the baseline questionnaire) or a physician diagnosis of gallstones or gallbladder disease (on the 1992 questionnaire). Persons classified with "gallbladder disease or stone" may or may not have had gallbladder surgery after 1982. Any surgery between 1982 and 1992 could have preceded or followed a possible colon polyp diagnosis.

We used unconditional, logistic regression to estimate for men and women separately the odds ratios (ORs) and 95\% confidence intervals (CIs) for the 10-year incidence of colon polyp diagnosis and the independent risk factors of interest. Each multivariate model included an adjustment for age (continuous), and categorical terms for race/ethnicity, educational attainment, and all the described risk factors or confounding variables.

We evaluated the role played by detection bias in this study by repeating similar multivariate analyses with two subgroups stratified according to their likelihood of polyp screening. Participants were considered to be at relatively high likelihood of polyp screening $(48.9 \%$ of the men and $35.3 \%$ of the women) if they reported a positive family history of colorectal cancer or high educational attainment ${ }^{28}$ (at least a college graduate). For men and women separately, we compared the ORs for risk factors of interest between the high-screening and low-screening subgroups.

We evaluated the effect-modifying role of gallbladder status by conducting similar multivariate analyses with 
two subgroups stratified according to the participant's report of a gallbladder without diagnosed disease or an abnormal gallbladder (i.e., surgically absent, containing a stone, or otherwise diseased). From the men's group, 6,354 participants $(8.7 \%)$ reported an abnormal gallbladder; from the women's group, 13,651 participants (16.8\%) reported an abnormal gallbladder. For men and women separately, we compared the ORs for risk factors of interest between the subgroups with clinically normal or abnormal gallbladders.

\section{RESULTS}

\section{Full Analytic Groups}

In the full analytic group, 7,504 men (10.3\%) and 5,111 women $(6.3 \%)$ reported being diagnosed by a physician with a first colon polyp between 1982 and 1992. The percentage reporting a first colon polyp rose with age and was consistently higher in persons with a family history of colorectal cancer (Table 1).

In logistic analyses fully adjusted for other potential risk factors, polyp occurrence was associated positively with baseline tobacco smoking history (Table $2 ; p<.0001$ for all smoking categories) and with baseline alcohol use of at least two drinks per day ( $p<.0001$ for men, $p=$ .003 for women). Compared with persons of typical healthy weight, those with high baseline body mass index $\left(28+\mathrm{kg} / \mathrm{m}^{2}\right)$ had a borderline increased polyp risk ( $p=$ .070 for men, $p=.072$ for women). Gallbladder surgery prior to baseline was also associated with an increased risk of polyp ( $p<.001$ ), and the association was even stronger with a diagnosis of gallbladder disease or stone in the absence of baseline gallbladder surgery ( $p<.0001)$.

Polyp occurrence was associated inversely with baseline, self-reported high exercise (Table 3; $p<.0001$ for men, $p=.087$ for women). Among women, aspirin use more than 10 times per month was associated with lower polyp risk ( $p=.003$ ), but this association was not observed for men $(p>4)$. Compared with nulliparous women, those who reported giving birth had a reduced colon polyp risk ( $p=$ .011 for parity $1-3, p=.003$ for parity $4+$ ).

In the fully adjusted logistic analyses, polyp risk remained associated (data not shown in the tables) with a family history of colorectal cancer both for one affected parent or sibling (men's OR 1.99; 95\% CI 1.81, 2.18; women's OR 1.82; 95\% CI 1.65, 2.01; both $p<.0001$ ) or for two or more affected parents or siblings (men's OR 2.73; CI 1.86, 4.00; women's OR 2.52; CI 1.71, 3.72; both $p<.0001)$. Compared with men who had completed a high school education, male college graduates had an increased polyp risk (OR 1.16; CI 1.10, 1.22; $p<.0001$ ), but women's risk was unrelated to their educational attainment $(p>3)$. Polyp risk was unrelated to nonwhite race/ethnicity $(p>.7)$ for both men and women.

There was a weak, inverse association (nonsignificant) between polyp occurrence and baseline high consumption of vegetables and fruit seen only among the women (compared with first decile, deciles 6 through 9 OR 0.91; 95\% CI 0.81, 1.02; $p=.089$; decile 10 OR 0.87; CI $0.75,1.01 ; p=.064)$. Polyp risk showed no association with vegetable and fruit consumption for men, nor with consumption of red meats, high-fiber foods, chicken and fish, or eggs for either men or women (all $p>$.2). High consumption of coffee $(4+$ cups/day) showed associations with polyp risk that were weak and inconsistent (compared with no coffee consumption, for men, OR 1.04; CI $0.96,1.13 ; p=.389$; for women, OR 0.91; CI 0.83, 1.00; $p=$.045). Polyp risk was not significantly associated with women's use at baseline of estrogen replacement therapy or with menopausal status, and there was no association for either men or women with use of a multivitamin supplement. Separate analyses (multivariate models not shown) tested the effect of supplementation with vitamins A, C, and E, but each of these vitamin preparations also had no association with the risk of colon polyp.

\section{Subgroup Analyses}

The high-screening subgroup (presumed to have greater exposure to polyp screening because of their family history of colorectal cancer or greater education) reported a higher crude polyp occurrence than did the lowscreening subgroup among men (11.2\% vs 9.4\%) and women $(6.6 \%$ vs $6.1 \%)$. However, multivariate analyses stratified according to high or low likelihood of polyp screening showed no important differences between high-

Table 1. Percentage of People Reporting a First Colon Polyp in the 1992 Survey by Gender, Age in 1982, and Family History of Colorectal Cancer

\begin{tabular}{|c|c|c|c|c|c|c|c|c|c|c|c|c|}
\hline \multirow[b]{2}{*}{$\begin{array}{l}\text { Age in } \\
1982\end{array}$} & \multicolumn{6}{|c|}{ Men } & \multicolumn{6}{|c|}{ Women } \\
\hline & $\begin{array}{l}\text { First } \\
\text { Polyp }\end{array}$ & $\begin{array}{l}\text { No } \\
\text { Polyp }\end{array}$ & $\begin{array}{c}\text { Percentage } \\
\text { with First Polyp }\end{array}$ & $\begin{array}{l}\text { First } \\
\text { Polyp }\end{array}$ & $\begin{array}{l}\text { No } \\
\text { Polyp }\end{array}$ & $\begin{array}{c}\text { Percentage } \\
\text { with First Polyp }\end{array}$ & $\begin{array}{l}\text { First } \\
\text { Polyp }\end{array}$ & $\begin{array}{l}\text { No } \\
\text { Polyp }\end{array}$ & $\begin{array}{c}\text { Percentage } \\
\text { with First Polyp }\end{array}$ & $\begin{array}{l}\text { First } \\
\text { Polyp }\end{array}$ & $\begin{array}{l}\text { No } \\
\text { Polyp }\end{array}$ & $\begin{array}{c}\text { Percentage } \\
\text { with First Polyp }\end{array}$ \\
\hline $40-44$ & 196 & 2,880 & 6.4 & 11 & 107 & 9.3 & 368 & 8,770 & 4.0 & 26 & 401 & 6.1 \\
\hline $45-49$ & 1,186 & 14,537 & 7.5 & 113 & 594 & 16.0 & 930 & 18,056 & 4.9 & 105 & 965 & 9.8 \\
\hline $60-64$ & 1,239 & 7,794 & 13.7 & 121 & 416 & 22.5 & 810 & 8,658 & 8.6 & 90 & 600 & 13.0 \\
\hline
\end{tabular}


Table 2. Risk Factors Associated Positively with Self-Reported Colon Polyps: Frequencies and Odds Ratios for Full Analytic Groups

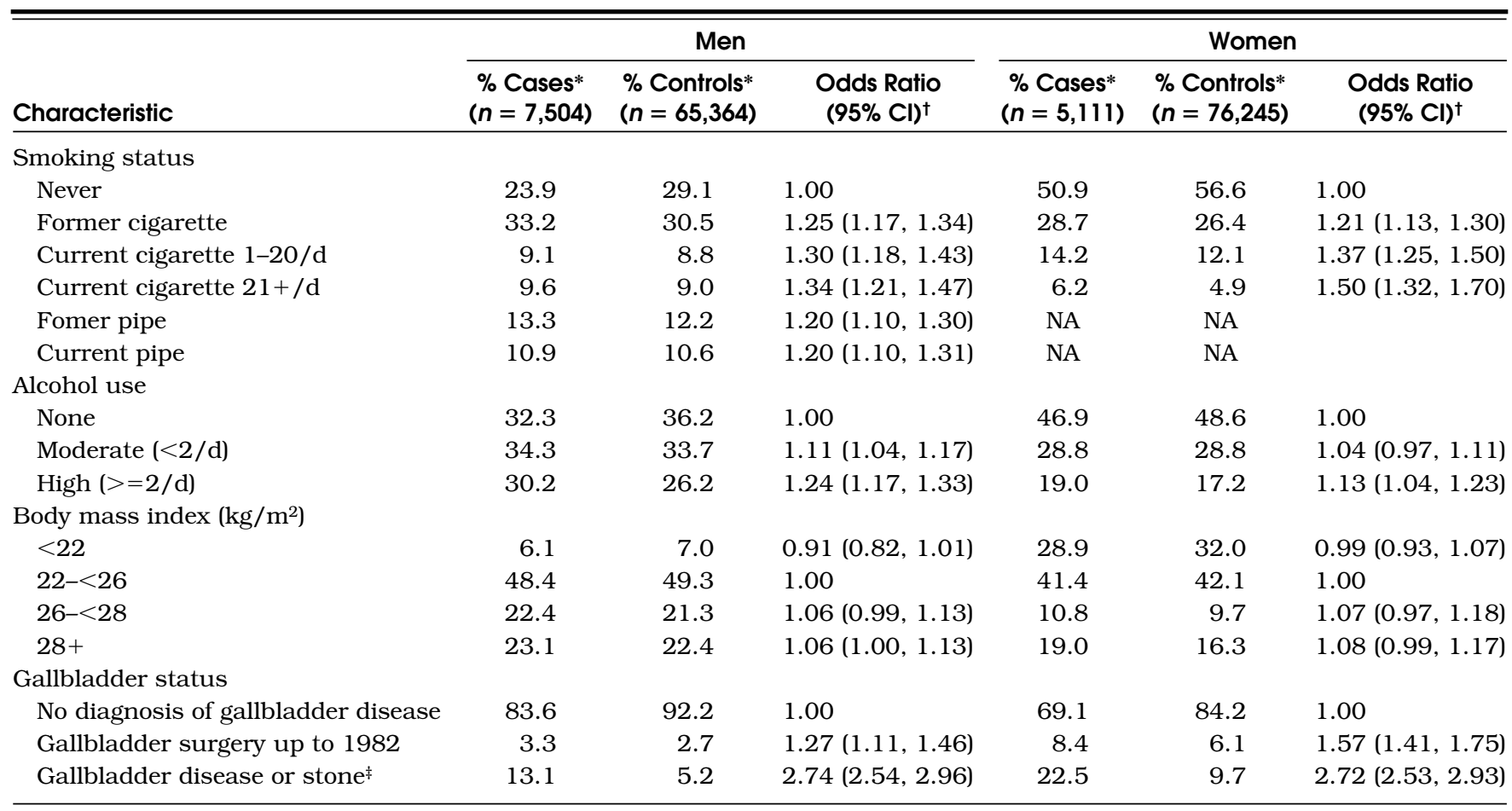

* Percentages may not add to 100 owing to missing data. NA indicates not available.

${ }^{\dagger}$ Logistic models are adjusted for age, education, race, gallbladder status, body mass index $\left(\mathrm{kg} / \mathrm{m}^{2}\right)$, exercise, smoking, alcohol consumption, coffee consumption, aspirin use, multivitamin use, family history of colorectal cancer, diet change, diet (eggs, vegetables, meat, fiber, and chicken plus fish), and for women, parity, estrogen replacement therapy, and menopausal status.

¥ Gallbladder disease may have been diagnosed between 1982 and 1992.

screening and low-screening subgroups with regard to each of the identified colon polyp risk factors.

The abnormal-gallbladder subgroup reported a crude polyp occurrence approximately twice that of the clinically normal-gallbladder subgroup among both men $(19.4 \%$ vs $9.4 \%)$ and women (11.6\% vs $5.2 \%)$. Table 4 shows for both men and women that the clinically normal-gallbladders subgroup and abnormal-gallbladder subgroup may have experienced different polyp risks associated with smoking status, body mass index, aspirin use, and red meat intake. For example, participants with clinically normal gallbladders continued to show highly significant associations between smoking and polyp occurrence, but those with gallbladders that were absent or diseased demonstrated substantially weaker associations between baseline smoking and polyp occurrence (interactions between smoking and gallbladder status: $p=.0001$ for men, $p=$ .035 for women). Contrary to the findings in participants with a clinically normal gallbladder, participants lacking a normal gallbladder avoided an increase in polyp risk otherwise associated with baseline high body mass index (interaction $p=.002$ for men and $p<.0001$ for women). At the same time, absence of a clinically normal gallbladder may have enhanced a polyp-protective effect related to aspirin use (interaction $p=.190$ for men and $p=.092$ for women) and possibly revealed an inverse association be- tween polyp occurrence and high consumption of red meats (women only, interaction $p=.083$ ).

\section{DISCUSSION}

The strengths of this study are its large size and the availability of risk-factor exposure information that was collected from the participants prospectively, prior to the recognition of a colon polyp. Beyond the established major risk factors for a colon polyp such as age and family history of colorectal cancer, we were able to explore simultaneously a variety of other risk factors, confounding variables, and effect modifiers.

A limitation of this study is that its participants, volunteers who completed a lengthy questionnaire on two occasions, may have overrepresented persons who were health-conscious and well or health-conscious and ill. Selection biases, therefore, may have influenced our findings or their generalizability. Our study was further limited by its lack of detail regarding the colon polyps (e.g., histologic type, size, diagnostic date, exact site of occurrence) and by the absence of information about the polypscreening experience of the participants. By not addressing polyp-screening experience, our analyses may have inadequately controlled for detection bias, i.e., confounding by factors that could influence screening likelihood or 
Table 3. Risk Factors Associated Inversely with Self-Reported Colon Polyps: Frequencies and Odds Ratios for Full Analytic Groups

\begin{tabular}{|c|c|c|c|c|c|c|}
\hline Characteristic & \multicolumn{3}{|c|}{ Men } & \multicolumn{3}{|c|}{ Women } \\
\hline Low & 28.5 & 25.9 & 1.00 & 28.3 & 27.0 & 1.00 \\
\hline Moderate & 60.7 & 61.3 & $0.90(0.85,0.96)$ & 65.5 & 66.6 & $0.94(0.88,1.01)$ \\
\hline High & 10.2 & 12.2 & $0.83(0.76,0.91)$ & 4.9 & 5.3 & $0.90(0.78,1.03)$ \\
\hline None & 34.3 & 33.4 & 1.00 & 29.5 & 27.9 & 1.00 \\
\hline Occasional to $9 / \mathrm{mo}$ & 33.5 & 33.8 & $0.99(0.93,1.05)$ & 33.9 & 35.5 & $0.96(0.89,1.03)$ \\
\hline $10+/ \mathrm{mo}$ & 9.9 & 9.4 & $0.97(0.89,1.06)$ & 10.3 & 11.0 & $0.85(0.77,0.95)$ \\
\hline \multicolumn{7}{|l|}{ Parity (live births) } \\
\hline Nulliparous & & & & 8.8 & 7.6 & 1.00 \\
\hline $1-3$ & & & & 59.8 & 60.6 & $0.87(0.79,0.97)$ \\
\hline
\end{tabular}

* Percentages may not add to 100 owing to missing data.

${ }^{\dagger}$ Logistic models are adjusted for age, education, race, gallbladder status, body mass index (kg/m²), excercise, smoking, alcohol consumption, coffee consumption, aspirin use, multivitamin use, family history of colorectal cancer, diet change, diet (eggs, vegetables, meat, fiber, and chicken plus fish), and for women, parity, estrogen replacement therapy, and menopausal status.

polyp recognition. We found little evidence for detection bias, however, in our analyses stratified into high-screening and low-screening subgroups. Most of the independent risk factors for colon polyp were similar in both subgroups. The Health Professionals Follow-up Study group similarly found no appreciable differences in men's polyp risk factors when they compared an analysis limited to 7,284 participants who had endoscopy to an analysis including 43,319 participants irrespective of endoscopy status. ${ }^{14}$

Our results support the accumulating evidence from case-control and prospective studies that tobacco smoking may increase the risk of colon polyp. ${ }^{29,30}$ The prospective Health Professionals Follow-up Study and Nurses' Health Study have provided smoking-associated relativerisk estimates for adenomatous polyps ${ }^{17,18}$ and hyperplastic polyps. ${ }^{5}$ These relative-risk estimates generally overlap each other, and they are similar to our OR estimates for polyps without specification of histologic type. Many of the previous studies did not adjust simultaneously for alcohol consumption, however, and none of them adjusted for gallbladder status as we have done.

The prospective studies of health professionals also suggested an independent risk associated with high alcohol consumption, ${ }^{5,15}$ an association that has been demonstrated for adenomatous polyps in some recent case-control studies, ${ }^{31-34}$ but not in others. ${ }^{26,35-40}$ Three case-control studies found an association between high alcohol consumption and adenomatous polyps among men, but not among women. ${ }^{41-43}$ It is possible that smoking acts as an initiator of polyp formation, ${ }^{30}$ whereas alcohol use acts later as a promoter of polyp growth. Evidence for this distinction may be found related to the younger age at which smoking exhibits its maximal effect, ${ }^{44}$ to recent smoking having a stronger relation with small (as opposed to large) adenomas, ${ }^{17,18,36}$ and to smoking's association with polyp recurrence. ${ }^{38,45}$ By contrast, alcohol use has a stronger relation to polyps among older persons ${ }^{44}$ and persons with large adenomas, ${ }^{36,43}$ and may not be related to polyp recurrence. ${ }^{38}$

The role of gallbladder status as a risk factor for colon polyp has not been reported in a prospective study, and the case-control studies addressing prior cholecystectomy have been difficult to interpret.12,13,46 Our findings in both men and women support those case-control studies that identified cholecystectomy as a risk for colon polyp diagnosis. ${ }^{4-50}$ To the best of our knowledge, there have been no prior reports that a gallbladder disease or stone (in the absence of cholecystectomy) was also associated with polyp risk. With or without cholecystectomy, a history of gallbladder disease may be a marker of visceral autonomic neuropathy, associated in turn both with impaired gallbladder emptying ${ }^{51}$ and with prolonged intestinal transit. Alternatively, these observations could suggest the existence of polyp initiators or promoters that are ordinarily attenuated by the acidification or concentration of bile that occurs in a normal gallbladder. ${ }^{52}$ We cannot rule out the possibility that some of our observed association between gallbladder status and colon polyp is due to detection bias, i.e., that the presence of an abdominal symptom results in greater medical scrutiny and, therefore, an increase in the diagnosis of both gallbladder disease and colon polyp.

The interaction between gallbladder status and other polyp risk factors (Table 4) suggests several pathophysiologic hypotheses that could be tested. For example, a 1995 report found that daily low-dose aspirin enhanced gallbladder motility in patients with gallstone disease although it did not alter the gallbladder ejection fraction in 
Table 4. Subgroup Analyses of the Association Between Colon Polyps and Various Exposures in Persons With and Without a Clinically Normal Gallbladder*

\begin{tabular}{|c|c|c|c|c|}
\hline \multirow[b]{2}{*}{ Characteristic } & \multicolumn{2}{|c|}{ Men } & \multicolumn{2}{|c|}{ Women } \\
\hline & Odds Ratio $(95 \% \mathrm{Cl})$ & Odds Ratio $(95 \% \mathrm{Cl})$ & Odds Ratio $(95 \% \mathrm{Cl})$ & Odds Ratio $(95 \% \mathrm{Cl})$ \\
\hline \multicolumn{5}{|l|}{ Smoking status } \\
\hline Never & 1.00 & 1.00 & 1.00 & 1.00 \\
\hline Current cigarette $1-20 / \mathrm{d}$ & $1.34(1.20,1.49)$ & $1.10(0.86,1.41)$ & $1.45(1.30,1.61)$ & $1.18(1.00,1.40)$ \\
\hline Current cigarette $21+/ d$ & $1.46(1.31,1.62)$ & $0.80(0.61,1.04)$ & $1.64(1.41,1.90)$ & $1.15(0.91,1.47)$ \\
\hline Former pipe & $1.25(1.14,1.37)$ & $0.93(0.75,1.16)$ & NA & NA \\
\hline Current pipe & $1.28(1.16,1.41)$ & $0.81(0.64,1.03)$ & NA & NA \\
\hline \multicolumn{5}{|l|}{ Body mass index $\left(\mathrm{kg} / \mathrm{m}^{2}\right)$} \\
\hline$<22$ & $0.88(0.79,0.98)$ & $1.20(0.89,1.61)$ & $0.92(0.85,1.00)$ & $1.35(1.17,1.55)$ \\
\hline \multicolumn{5}{|l|}{ Aspirin use } \\
\hline None & 1.00 & 1.00 & 1.00 & 1.00 \\
\hline Occasional to $9 / \mathrm{mo}$ & $1.00(0.94,1.07)$ & $0.90(0.77,1.06)$ & $0.96(0.88,1.04)$ & $0.96(0.84,1.10)$ \\
\hline $10+/ \mathrm{mo}$ & $1.00(0.91,1.10)$ & $0.80(0.64,1.00)$ & $0.90(0.80,1.02)$ & $0.76(0.63,0.92)$ \\
\hline \multicolumn{5}{|l|}{ Meat intake (decile) } \\
\hline 1st (lowest) & 1.00 & 1.00 & 1.00 & 1.00 \\
\hline 2nd-5th & $0.98(0.88,1.09)$ & $0.86(0.66,1.11)$ & $1.13(0.99,1.29)$ & $0.76(0.63,0.93)$ \\
\hline 6th-9th & $1.03(0.92,1.15)$ & $0.84(0.65,1.10)$ & $1.15(1.00,1.32)$ & $0.80(0.66,0.98)$ \\
\hline 10th (highest) & $0.97(0.85,1.12)$ & $0.86(0.62,1.20)$ & $1.25(1.06,1.48)$ & $0.80(0.62,1.03)$ \\
\hline
\end{tabular}

* Logistic models are adjusted for age, education, race, body mass index $\left(\mathrm{kg} / \mathrm{m}^{2}\right)$, exercise, smoking, alcohol consumption, coffee consumption, aspirin use, multivitamin use, family history of colorectal cancer, diet change, diet (eggs, vegetables, meat, fiber, and chicken plus fish), and for women, parity, estrogen replacement therapy, and menopausal status. NA indicates not available.

healthy subjects. ${ }^{53}$ One might speculate that aspirin's protective role against polyp formation in part reflects its restoring normal function to persons who otherwise have impaired gallbladder motility. In light of these epidemiologic observations, we hope that investigators from other disciplines will focus new attention on the gallbladder's role in modifying tumorigenesis of the distal intestine.

In agreement with prospective studies, ${ }^{20,22}$ we found independent polyp risks related to overweight and physical inactivity. Our relatively simple baseline dietary histories, however, revealed only minimal associations between groups of foods and polyp diagnosis, whereas the more elaborate dietary questionnaire used in the male Health Professionals Follow-up Study demonstrated moderate associations with intake of red meat or animal fats (positive) and with dietary fiber (inverse). ${ }^{14}$ The reduced polyp risk (borderline significance) associated with high vegetable and fruit intake among women in our analytic group is consistent with recent case-control studies. ${ }^{54,55}$

In our women's group we found perhaps the first evidence of reduced polyp risk associated with high parity. The size of this protective effect was small, however, and deserves study in other populations. We also found in the women's group a small reduction in polyp risk associated with aspirin use, an observation previously reported pro- spectively among male health professionals, ${ }^{16}$ among female nurses, ${ }^{21}$ and in a study of polyp recurrence. ${ }^{56} \mathrm{We}$ did not, however, find an inverse association between aspirin use and polyps among the men in our study.

Our observational study has identified candidate patient characteristics, easily determined through simple questions or observations, that might enhance the costeffectiveness of screening programs for colon polyp. We hope these findings and our brief discussion will be useful to primary care researchers, but the strength of the associations reported here can only be interpreted tentatively. Future investigations may be better able to address the lack of polyp detail, the detection biases, and the selection biases that may have influenced our results. Our findings suggest, nevertheless, that beyond persons with a personal or first-degree family history of colorectal neoplasia or known to have inflammatory bowel disease, the highest yields for polyp screening may be found among men or women who are (or were) smokers, those who consume at least two alcoholic drinks per day, and those who are overweight. The screening yield may be less among men who exercise regularly and among women who have a high intake of fruits and vegetables, are regular aspirin users, or have borne many children. Further insights are needed that address the altered colon polyp risk among 
patients with a history of cholecystectomy or gallbladder disease.

The authors are grateful to the thousands of volunteers throughout the Divisions of the American Cancer Society who donated their time and energy to CPS-II. Many staff members of the American Cancer Society's National Home Office participated in the collection, management, and analysis of these data.

\section{REFERENCES}

1. Schappert SM. National Ambulatory Medical Care Survey: 1994 Summary. Advance Data from Vital and Health Statistics; no. 273. Hyattsville, Md: National Center for Health Statistics; 1996:1-20.

2. Muto T, Bussey HJR, Morson BC. The evolution of cancer of the colon and rectum. Cancer. 1975;36:2251-70.

3. Jass JR. Do all colorectal carcinomas arise in preexisting adenomas? World J Surg. 1989;13:45-51.

4. Winawer SJ, Zauber AG, Ho MN, et al. Prevention of colorectal cancer by colonoscopic polypectomy. The National Polyp Study Workgroup. N Engl J Med. 1993;329:1977-81.

5. Kearney J, Giovannucci E, Rimm EB, et al. Diet, alcohol, and smoking and the occurrence of hyperplastic polyps of the colon and rectum (United States). Cancer Causes Control. 1995;6:45-56.

6. Winawer SJ, St John DJ, Bond JH, et al. Prevention of colorectal cancer: guidelines based on new data. WHO Collaborating Center for the Prevention of Colorectal Cancer. Bull World Health Organ. 1995;73:7-10.

7. US Preventive Services Task Force. Guide to Clinical Preventive Services. 2nd ed. Baltimore, Md: Williams \& Wilkins; 1996.

8. Winawer SJ, Fletcher RH, Miller L, et al. Colorectal cancer screening: clinical guidelines and rationale. Gastroenterology. 1997;112: 594-642.

9. Burke W, Petersen G, Lynch P, et al. Recommendations for followup care of individuals with an inherited predisposition to cancer: I. Hereditary nonpolyposis colon cancer. Consensus Statement. JAMA. 1997;277:915-9.

10. Colorectal Cancer Screening: Evidence Report No. 1. Rockville, Md: Agency for Health Care Policy and Research; 1997. Report AHCPR97-0300.

11. Mulcahy HE, Farthing MJG, O'Donoghue DP. Screening for asymptomatic colorectal cancer. BMJ. 1997;314:285-91.

12. Neugut AI, Jacobson JS, DeViVo I. Epidemiology of colorectal adenomatous polyps. Cancer Epidemiol Biomarkers Prev. 1993;2: 159-76.

13. Peipins LA, Sandler RS. Epidemiology of colorectal adenomas. Epidemiol Rev. 1994;16:273-97.

14. Giovannucci E, Stampfer MJ, Colditz G, Rimm EB, Willett WC. Relationship of diet to risk of colorectal adenoma in men. J Natl Cancer Inst. 1992;84:91-8.

15. Giovannucci E, Stampfer MJ, Colditz GA, et al. Folate, methionine, and alcohol intake and risk of colorectal adenoma. J Natl Cancer Inst. 1993;85:875-84.

16. Giovannucci E, Rimm EB, Stampfer MJ, Colditz GA, Ascherio A, Willett WC. Aspirin use and the risk for colorectal cancer and adenoma in male health professionals. Ann Intern Med. 1994;121: 241-6.

17. Giovannucci E, Rimm EB, Stampfer MJ, et al. A prospective study of cigarette smoking and risk of colorectal adenoma and colorectal cancer in U.S. men. J Natl Cancer Inst. 1994;86:183-91.

18. Giovannucci E, Colditz GA, Stampfer MJ, et al. A prospective study of cigarette smoking and risk of colorectal adenoma and colorectal cancer in U.S. women. J Natl Cancer Inst. 1994;86:192-9.

19. Kampman E, Giovannucci E, van't Veer P, et al. Calcium, vitamin
D, dairy foods, and the occurrence of colorectal adenomas among men and women in two prospective studies. Am J Epidemiol. 1994;139:16-29.

20. Giovannucci E, Ascherio A, Rimm EB, Colditz GA, Stampfer MJ, Willett WC. Physical activity, obesity, and risk for colon cancer and adenoma in men. Ann Intern Med. 1995;122:327-34.

21. Giovannucci E, Egan KM, Hunter DJ, et al. Aspirin and the risk of colorectal cancer in women. N Engl J Med. 1995;333:609-14.

22. Giovannucci E, Colditz GA, Stampfer MJ, Willett WC. Physical activity, obesity, and risk of colorectal adenoma in women (United States). Cancer Causes Control. 1996;7:253-63.

23. Garfinkel L, Heath CW. Cancer Prevention Study II: the American Cancer Society prospective study. Stat Bull. 1992;73:21-9.

24. Baron JA, Greenberg ER, Haile R, Mandel J, Sandler RS, Mott L. Coffee and tea and the risk of recurrent colorectal adenomas. Cancer Epidemiol Biomarkers Prev. 1997;6:7-10.

25. Baron JA, Gerhardsson de Verdier M, Ekbom A. Coffee, tea, tobacco, and cancer of the large bowel. Cancer Epidemiol Biomarkers Prev. 1994;3:565-70.

26. Benito E, Cabeza E, Moreno V, Obrador A, Bosch FX. Diet and colorectal adenomas: a case-control study in Majorca. Int $\mathrm{J}$ Cancer. 1993;55:213-9.

27. Steinmetz KA, Potter JD. Egg consumption and cancer of the colon and rectum. Eur J Cancer Prev. 1994;3:237-45.

28. Anderson LM, May DS. Has the use of cervical, breast, and colorectal cancer screening increased in the United States? Am J Public Health. 1995;85:840-2.

29. Heineman EF, Zahm SH, McLaughlin JK, Vaught JB. Increased risk of colorectal cancer among smokers: results of a 26-year follow-up of US veterans and a review. Int J Cancer. 1994;59:728-38.

30. Giovannucci E, Martinez ME. Tobacco, colorectal cancer, and adenomas. J Natl Cancer Inst. 1996;88:1717-30.

31. Kono S, Ikeda N, Yanai F, Shinchi K, Imanishi K. Alcoholic beverages and adenomatous polyps of the sigmoid colon: a study of male self-defence officials in Japan. Int J Epidemiol. 1990; 19:848-52.

32. Cope GF, Wyatt JI, Pinder IF, Lee PN, Heatley RV, Kelleher J. Alcohol consumption in patients with colorectal adenomatous polyps. Gut. 1991;32:70-2.

33. Honjo S, Kono S, Shinchi K, et al. The relation of smoking, alcohol use and obesity to risk of sigmoid colon and rectal adenomas. Jpn J Cancer Res. 1995;86:1019-26.

34. Martinez ME, McPherson RS, Annegers JF, Levin B. Cigarette smoking and alcohol consumption as risk factors for colorectal adenomatous polyps. J Natl Cancer Inst. 1995;87;274-9.

35. Riboli E, Cornee J, Macquart-Moulin G, Kaaks R, Casagrande C, Guyader M. Cancer and polyps of the colorectum and lifetime consumption of beer and other alcoholic beverages. Am J Epidemiol. 1991;133:157-66.

36. Honjo S, Kono S, Shinchi K, Imanishi K, Hirohata T. Cigarette smoking, alcohol use and adenomatous polyps of the sigmoid colon. Jpn J Cancer Res. 1992;83:806-11.

37. Lee WC, Neugut AI, Garbowski GC, et al. Cigarettes, alcohol, coffee, and caffeine as risk factors for colorectal adenomatous polyps. Ann Epidemiol. 1993;3:239-44.

38. Jacobson JS, Neugut AI, Murray T, et al. Cigarette smoking and other behavioral risk factors for recurrence of colorectal adenomatous polyps (New York City, NY, USA). Cancer Causes Control. 1994;5:215-20.

39. Todoroki I, Kono S, Shinchi K, et al. Relationship of cigarette smoking, alcohol use, and dietary habits with sigmoid colon adenomas. Ann Epidemiol. 1995;5:478-83.

40. Longnecker MP, Chen M-J, Probst-Hensch NM, et al. Alcohol and smoking in relation to the prevalence of adenomatous colorectal polyps detected at sigmoidoscopy. Epidemiology. 1996;7:275-80.

41. Kune GA, Kune S, Read A, MacGowan K, Penfold C, Watson LF. Colorectal polyps, diet, alcohol, and family history of colorectal cancer: a case-control study. Nutr Cancer. 1991;16:25-30.

42. Sandler RS, Lyles CM, McAuliffe C, Woosley JT, Kupper LL. Ciga- 
rette smoking, alcohol, and the risk of colorectal adenomas. Gastroenterology. 1993;104:1445-51.

43. Boutron MC, Faivre J, Dop MC, Quipourt V, Senesse P. Tobacco, alcohol and colorectal tumors: a multistep process. Am J Epidemiol. 1995; 141:1038-46.

44. Kikendall JW, Bowen PE, Burgess MB, Magnetti C, Woodward J, Langenberg P. Cigarettes and alcohol as independent risk factors for colonic adenomas. Gastroenterology. 1989;97:660-4.

45. Hoff G, Vatn MH, Larsen S. Relationship between tobacco smoking and colorectal polyps. Scand J Gastroenterol. 1987;22:13-6.

46. Giovannucci E, Colditz GA, Stampfer MJ. A meta-analysis of cholecystectomy and risk of colorectal cancer. Gastroenterology. 1993;105:130-41.

47. Llamas KJ, Torlach LG, Ward M, Bain C. Cholecystectomy and adenomatous polyps of the large bowel. Gut. 1986;27:1181-5.

48. Sandler RS, Martin ZZ, Carlton NM, Holland KL. Adenomas of the large bowel after cholecystectomy. A case-control study. Dig Dis Sci. 1988;33:1178-84.

49. Moorehead RJ, Mills JO, Wilson HK, McKelvey ST. Cholecystectomy and the development of colorectal neoplasia: a prospective study. Ann R Coll Surg Engl. 1989;71:37-9.
50. Giorgio P, Lorusso D, Di Matteo G, Giorgio I. Colecistectomia e polipi adenomatosi del colon-retto. Minerva Chir. 1989;44:1489-91.

51. Stone BG, Gavaler JS, Belle SH, et al. Impairment of gallbladder emptying in diabetes mellitus. Gastroenterology. 1988;95:170-6.

52. Shiffman ML, Sugerman HJ, Moore EW. Human gallbladder mucosal function: effect of concentration and acidification of bile on cholesterol and calcium solubility. Gastroenterology. 1990;99: 1452-9.

53. Das A, Baijal SS, Saraswat VA. The effect of aspirin on gallbladder motility in patients with gallstone disease: a randomized, doubleblind, placebo-controlled trial of two dosage schedules. Dig Dis Sci. 1995;40:1782-5.

54. Sandler RS, Lyles CM, Peipins LA, McAuliffe CA, Woosley JT, Kupper LL. Diet and risk of colorectal adenomas: macronutrients, cholesterol, and fiber. J Natl Cancer Inst. 1993;85:884-91.

55. Witte JS, Longnecker MP, Bird CL, Lee ER, Frankl HD, Haile RW. Relation of vegetable, fruit, and grain consumption to colorectal adenomatous polyps. Am J Epidemiol. 1996;144:1015-25.

56. Greenberg ER, Baron JA, Freeman D Jr, Mandel JS, Haile R. Reduced risk of large-bowel adenomas among aspirin users. The Polyp Prevention Study Group. J Natl Cancer Inst. 1993;85:912-6.

\title{
ANNOUNCEMENT
}

\section{SGIM Website}

Please visit the Society of General Internal Medicine on their World-Wide Website. SGIM is located at

\author{
http://www.sgim.org
}

